\title{
Attributing psychopathology to systemic lupus erythematosus: some methodological considerations
}

\author{
Grant L Iverson, Lance M McCracken
}

Department of

Psychology,

West Virginia University,

Morgantown, WV, USA

$G$ L Iverson

L M McCracken

Correspondence to:

Grant L Iverson,

Department of Psychology,

104 Oglebay Hall,

West Virginia University,

Morgantown, WV 26506 ,

USA

Accepted for publication

12 February 1991
The presence of psychiatric problems in patients with systemic lupus erythematosus (SLE) is frequently discussed. ${ }^{1-14}$ These psychiatric disorders are commonly believed to be an integral part of the disease process, and, in fact, the 1982 revised criteria for diagnosis include psychosis. ${ }^{15}$ The purpose of this review is to comment on the current beliefs about the relation between SLE and psychiatric manifestations. There is little doubt that patients with this debilitating disease have psychiatric symptoms. What is unclear from the available research, however, is the prevalence of such problems and the extent to which psychiatric difficulties can be directly attributed to the disease process. It is our intention to highlight the methodological inadequacies of selected studies and to encourage more sound investigations which may elucidate the critical variables relevant to such discussions.

In a review of work published in the 1950s and 1960s, Gurland et al delineated the methodological problems of previous investigations of the psychiatric sequelae of SLE. ${ }^{16}$ These authors noted that there was a dramatic increase in the reported incidence of psychiatric problems in the 1960s compared with the 1950s. There are numerous possible hypotheses for this, but few are related to the actual occurrence of psychopathology in these patients. For example, these findings may be the result of a greater awareness of the association between psychopathology and SLE, in addition to an influx of psychiatrists working on this topic. Another finding was that the percentage of psychiatric problems in patients with lupus varies with the specialty of the senior author, with psychiatrists reporting much higher figures than dermatologists or those concerned with internal medicine. This review also revealed numerous sampling and design problems. These methodological flaws are still found in more recent studies.

Current texts in rheumatology ${ }^{17-22}$ were considered to select studies which are commonly cited as illustrations and evidence for psychiatric sequelae in patients with SLE. The table gives a synopsis of the methodological problems of five frequently cited investigations.

Seven methodological deficiencies are particularly notable when reviewing these studies. There is a recurrent lack of specificity in classifying patients with neuropsychiatric lupus. Articles often do not distinguish between neurological and psychiatric disorders. Consequently, most samples are so heterogeneous, and small, that meaningful conclusions are difficult to obtain. The methods and criteria used to classify the various psychiatric symptoms are poorly described. The past two decades have seen dramatic changes in diagnostic criteria, which seriously limits comparisons across studies, and indicates the need for caution in interpreting earlier findings. Arguably, the standardisation, reliability, and validity of the psychiatric assessment procedures are questionable in all of the studies reviewed. The table notes this limitation only in those studies which provided some descriptions of their assessment methods.

There are many sampling problems in reported

Methodological limitations of selected studies of the psychiatric sequelae of systemic lupus erythematosus

\begin{tabular}{|c|c|c|c|c|c|c|c|c|c|c|c|c|c|c|}
\hline \multirow[t]{3}{*}{ Reference } & \multirow[t]{3}{*}{ Number of patients } & \multirow{3}{*}{$\begin{array}{l}\text { Number of patients } \\
\text { with psychiatric symptoms }\end{array}$} & \multicolumn{12}{|c|}{ Methodological limitations* } \\
\hline & & & \multirow{2}{*}{$\frac{\text { Sampling }}{1}$} & \multicolumn{11}{|c|}{ Measurement design and analysis } \\
\hline & & & & 2 & 3 & 4 & 5 & 6 & 7 & 8 & 9 & 10 & 11 & 12 \\
\hline 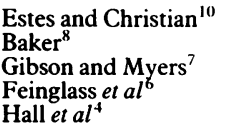 & $\begin{array}{r}150 \\
17 \\
80 \\
140 \\
56\end{array}$ & $\frac{41}{17} \dagger$ & $\begin{array}{l}\times \\
\times \\
\times \\
\times \\
\times \\
\times\end{array}$ & $\begin{array}{l}\times \\
\times\end{array}$ & $\begin{array}{l}\times \\
\times \\
\times \\
\times\end{array}$ & $x$ & $\begin{array}{l}x \\
x\end{array}$ & $\begin{array}{l}\times \\
\times \\
\times\end{array}$ & $\begin{array}{l}\times \\
\times \\
\times \\
\times\end{array}$ & $\begin{array}{l}\times \\
\times \\
\times \\
\times \\
\times \\
\times\end{array}$ & $\begin{array}{l}\times \\
\times \\
\times \\
\times \\
\times \\
\times\end{array}$ & $\times$ & $x$ & \\
\hline \multicolumn{15}{|c|}{$\begin{array}{l}\text { Limitations are listed below: } \\
1 \text { Random sample not obtained-for example, sample obtained from a single hospital or specialty consultancy such as psychiatry or dermatology, or composed of only } \\
\text { inpatients or outpatients. } \\
2 \text { Psychiatric diagnostic system not specified. } \\
3 \text { Psychiatric assessment methods not clearly defined. } \\
4 \text { Psychiatric assessment procedures lack adequate standardisation, reliability, or validity. } \\
5 \text { Diagnosis not made by a qualified professional or not based on clearly defined data. } \\
6 \text { Use of archival data allows inadequate control of data collection and may be unreliable. } \\
7 \text { No comparison group. } \\
8 \text { Cross validation procedures not used. } \\
9 \text { Base rates for psychiatric disorders in normal or other medical populations not considered. } \\
10 \text { Inappropriate generalisations based on limited sample. } \\
11 \text { Causal statements based on correlational data are inappropriate. } \\
12 \text { Improper or inaccurate use or interpretation of statistics. }\end{array}$} \\
\hline
\end{tabular}


studies. Some authors make inappropriate generalisations based on limited samples. Other samples are biased by representing a single hospital or clinic. Results from an inpatient sample may not readily generalise to all patients with SLE. Also, many studies do not include comparison groups, nor is base rate information reported. Without these data it is difficult to determine if the presence and frequency of psychiatric problems in patients with SLE differs from other medical populations or the general population. In the studies evaluated, statistics were sometimes erroneously interpreted. Finally, the cross sectional and correlational designs frequently used do not support conclusions regarding the cause of the disease. Inappropriate inferences of the cause of SLE were explåcit ${ }^{6}$ and implicit $^{4}$ in the studies reviewed.

It is unclear whether the psychopathology is a direct manifestation of the disease process or a function of disease related challenges which overwhelm the patient's ability to cope. There is some evidence that patients with SLE may not differ from normal subjects or other patients with chronic diseases in terms of psychiatric symptoms. For example, Allen and Glicksman ${ }^{23}$ conducted a large survey using the profile of mood states and found that patients with SLE did not differ from control subjects in the normative sample on measures of tension, depression, and anger. Moreover, they showed significantly less distress on these variables compared with psychiatric outpatients who were used as normal subjects. These workers then compared patients with SLE to patients with discoid lupus. These groups did not differ on any psychiatric variable. The results of this investigation suggest that roughly $25 \%$ of patients with lupus experienced significant psychiatric distress. More importantly, this disturbance does not appear to be related to the systemic nature of the disease, given the concordance with the distress noted in the patients with discoid lupus. These authors asserted the aetiological significance of psychological stress for the psychiatric disturbance.

Kremer $e t a l^{5}$ studied a sample of 37 patients with SLE and concluded that $46 \%$ had current psychopathology as assessed by a standard psychiatric interview. On the brief psychiatric rating scale, $68 \%$ of patients had at least one score of four (moderate) or greater. It appears that most of the psychopathology in this study is mild in nature, as seen by limited functional impairment. On the global assessment scale, only $29 \%$ of the subjects scored below a 70 (some mild symptoms). To evaluate the relationship between the disease and psychiatric distress these workers ran a series (624) of correlations between various indices of the severity of SLE and degree of psychopathology. They found no more significant correlations than would be expected by chance. Therefore, in that study, psychopathology was not associated with disease activity.

Given the serious methodological limitations in the frequently cited investigations noted in the table, the continued reliance on them for establishing the presence and frequency of psychiatric dysfunction in patients with SLE, as well as attributing this disturbance to the disease, is contraindicated. The conclusions of those citing this work have often exceeded those by the original authors, and at times represent inferential leaps beyond the data available. The unequivocal acceptance of the validity of such conclusions violates accepted standards of scholarship, misleads readers of the research reports, and may perpetuate inaccuracies in current scientific knowledge. Moreover, the findings by Allen and Glicksman ${ }^{23}$ and Kremer et $a l^{5}$ have implications for the medical management of patients presenting with psychiatric distress. A belief that psychiatric symptoms represent a direct manifestation of the disease process indicates medical intervention. However, this intervention may not reduce these symptoms if they are the result of ineffective coping strategies in reaction to permanent changes in lifestyle. What is needed are more methodologically sound investigations which are designed to elucidate the relative contribution of disease pathology and psychosocial variables to the patient's psychological state.

1 Darby P L, Schmidt P J. Psychiatric consultations in rheumatology: a review of 100 cases. Can f Psychiatry 1988; 33: $290-2$.

2 Wallace D J. The role of stress and trauma in rheumatoid arthritis and systemic lupus erythematosus. Semin Arthritis Rheum 1987; 16: 153-7.

3 Rogers M P. Psychiatric aspects. In: Schur P H, ed. The clinical management of systemic lupus erythematosus. New York: Grune \& Stratton, 1983: 189-210.

4 Hall R C, Stikney S K, Gardner E R. Psychiatric symptoms in patients with systemic lupus erythematosus. Psychosomatics 1981; 22: 15-24.

5 Kremer J M, Rynes R I, Bartholomew L E, et al. Nonorganic, non-psychotic psychopathology (NONPP) in patients with systemic lupus erythematosus. Semin Arthritis Rheum 1981; 11: 182-9.

6 Feinglass E J, Arnett F C, Dorsch C A, Zizic T M, Stevens $M$ B. Neuropsychiatric manifestations of systemic lupus erythematosus: diagnosis, clinical spectrum, and relationships to other features of the disease. Medicine (Baltimore) ships to other feat
1976; 55: 323-39.

7 Gibson T, Myers A R. Nervous system involvement in systemic lupus erythematosus. Ann Rheum Dis 1976; 35: 398-406.

8 Baker M. Psychopathology in SLE. Semin Arthritis Rheum 1973; 3: 95-110.

9 Baker M, Hadler N, Whitaker J N, Dunner D L, Gerwin R D, Decker J L. Psychopathology in systemic lupus erythematosus: II relation to clinical observations, corticosteroid administration and cerebrospinal fluid C4. Semin Arthritis Rheum 1973; 3: 111-26.

10 Estes D, Christian C L. The natural history of systemic lupus erythematosus by prospective analysis. Medicine (Baltimore) 1971; 50: 85-95.

11 Heine B E. Psychiatric aspects of systemic lupus erythematosus. Acta Psychiatr Scand 1969; 45: 307-26.

12 Otto R, Mackay I R. Psychosocial and emotional disturbance in systemic lupus erythematosus. Med $\mathcal{F}$ Aust 1967; 2: 488-93.

13 Stern M, Robbins E S. Psychoses in systemic lupus erythematosus. Arch Gen Psychiatry 1960; 3: 205-12.

14 O'Connor J F. Psychosis associated with systemic lupus erythematosus. Ann Intern Med 1959; 51: 526-36.

15 Tan E M, Cohen A S, Fries J F, et al. The 1982 revised criteria for the classification of systemic lupus erythematosus. Arthritis Rheum 1982; 25: 1271-7.

16 Gurland B J, Ganz V F, Fleiss J L, et al. The study of the psychiatric symptoms of systemic lupus erythematosus. Psychosom Med 1972; 34: 199-206.

17 Melvin J L, ed. Rheumatic disease in the adult and child: occupational therapy and rehabilitation. 3rd ed. Philadelphia: F A Davis, 1989.

18 Smolen J S, Zielinski C C, eds. Systemic lupus erythematosus: clinical and experimental aspects. Berlin: Springer-Verlag, 1987.

19 Ball G V, Koopman W J. Clinical rheumatology. Philadelphia: Saunders, 1986

20 Scott J T, ed. Copeman's textbook of the rheumatic diseases. Vol. 2, 6th ed. London: Churchill Livingstone, 1986.

21 Kelley W N, Harris E D, Ruddy S, Sledge C B, eds. Textbook of rheumatology, 2nd ed. Philadelphia: Saunders, 1985.

22 Schur $\mathbf{P} \mathbf{H}$, ed. The clinical management of systemic lupus erythematosus. New York: Grune \& Stratton, 1983.

23 Allen $T$. Glicksman $M$. Psychologic involvement in systemic lupus erythematosus: a psychometric approach. Clinical Rheumatology in Practice 1986: 64-70. 